\title{
Recent results based on continuous GPS observations of the GIA process in Fennoscandia from BIFROST
}

\author{
Martin Lidberg, ${ }^{\mathrm{a}, \mathrm{b}, *}$, Jan M. Johansson ${ }^{\mathrm{a}, \mathrm{c}}$, Hans-Georg Scherneck ${ }^{\mathrm{a}}$, Glenn A. Milne ${ }^{\mathrm{d}}$ \\ a Department of Radio and Space Science, Chalmers University of Technology Onsala Space \\ Observatory, SE-439 92 Onsala, Sweden \\ ${ }^{\mathrm{b}}$ Lantmäteriet (The Swedish Mapping, Cadastre and Land Registration Authority) SE-801 82 Gävle, \\ Sweden \\ ${ }^{c}$ SP Technical Research Institute of Sweden, Box 857, SE-501 15 Borås Sweden \\ ${ }^{\mathrm{d}}$ Department of Earth Sciences, University of Ottawa, Canada \\ * Corresponding author. E-mail address: martin.lidberg@1m.se
}

\begin{abstract}
We present the latest 3D velocity field of the Fennoscandian Glacial Isostatic Adjustment (GIA) process from BIFROST. It is derived from more than 4800 days (13 years) of data at more than 80 permanent GPS sites. We use the GAMIT/GLOBK and the GIPSY/OASIS II software packages for GPS analysis and compare the results. The solution has an internal accuracy at the level of 0.2 $\mathrm{mm} / \mathrm{yr}$ (1 sigma) for horizontal velocities at the best sites. We also present a revised GIA prediction model. At the best sites, the optimal model agrees with the observations to within $0.4 \mathrm{~mm} / \mathrm{yr}$.

However, the model systematically overpredicts the magnitude of horizontal rates in the north. We discuss limitations in computed and presented GNSS station velocities, where especially possible instability over time causing non-linear pattern in vertical time series are considered. In extension, preliminary results from an investigation applying revised analysis strategies on a sparse subset of the data base are presented, indicating possible improvements for the future.
\end{abstract}

Keywords: postglacial adjustmet, GIA, GPS, reference frame, ITRF2000, ITRF2005, GAMIT/GLOBK.

\section{Introduction}

The BIFROST (Baseline Inferences for Fennoscandian Rebound Observations Sea Level and Tectonics) project was started in 1993. The first primary goal was to establish a new and useful three-dimensional measurement of the movements in the earth crust based on GNSS-observations, able to constrain models of the GIA (glacial isostatic adjustment) process in Fennoscandia.

Station velocities based on analysis of observations at permanent GPS stations in Sweden and Finland from the period August 1993 to May 2000 were presented in Johansson et al. (2002) and Scherneck et al. (2002) together with a thorough description of the BIFROST network. These velocities have then been used to constrain a viscoelastic self-gravitating model of the 
Fennoscandian GIA process (Milne et al. 2001, 2004). Updated station velocities were presented in Lidberg et al. (2007), based on data from the period 1996 to mid 2004. Some additional sites in Norway, Denmark and northern Europe were also included in this solution. The early phase of the BIFROST effort, especially up to mid 1996, comprised a period of intensive development and hardware changes at the GPS sites. The changes in hardware installation have resulted in transitional shifts in the position time series. By avoiding the period up to mid 1996 the solution in Lidberg et al. (2007) shows smaller uncertainties in station velocity compared to Johansson et al. (2002).

In Lidberg et al. (2008) the complete set of BIFROST data up to November 2006 were reanalyzed. The extended observation period allowed for including of some of the recently established GPS sites, resulting in a denser sampling of the GIA process within the study area. Differences in results based on different versions of the International Terrestrial Reference Frame (ITRF2000, Altamimi et al. 2002, and ITRF2005, Altamimi et al. 2007) were investigated and discussed extensively, as well as the effect of systematic errors in the GPS analysis on the position time series. A comparison to an updated version of the GIA prediction model was also presented. However, no numerical values of the estimated station velocities were given in Lidberg et al. (2008).

The purpose of this paper is to give an overview of published GNSS station velocity results from BIFROST, including two versions of the GIA prediction model. As a service to readers, and of special importance for a project like DynaQlim (Poutanen et al. this issue), we give numerical velocity values of analysed GNSS stations, together with results from advanced methods to estimate the uncertainty of derived velocities. We also stress the sensitivity of GNSS derived station velocities to reference frame issues and observation level modelling, and describe some possible causes for the non-linearity found in the position time series, especially at sites located in the north. The site velocity data set is further investigated for the determination of a Fennoscandian strain rate field in Scherneck et al. (2009, this issue).

\section{The extended BIFROST GPS network}

The BIFROST GPS network is composed of the permanent GPS network of Sweden (SWEPOS ${ }^{\mathrm{TM}}$, SWEPOS 2009 /online/) and Finland (FinnRef®, FGI 2009 /online/). This study also includes permanent GPS stations in Norway (SATREF®, SATREF 2009 /online/) and Denmark, as well as a selection of stations in northern Europe that contribute to the EUREF Permanent Network (EPN) (EUREF 2009 /online/). 


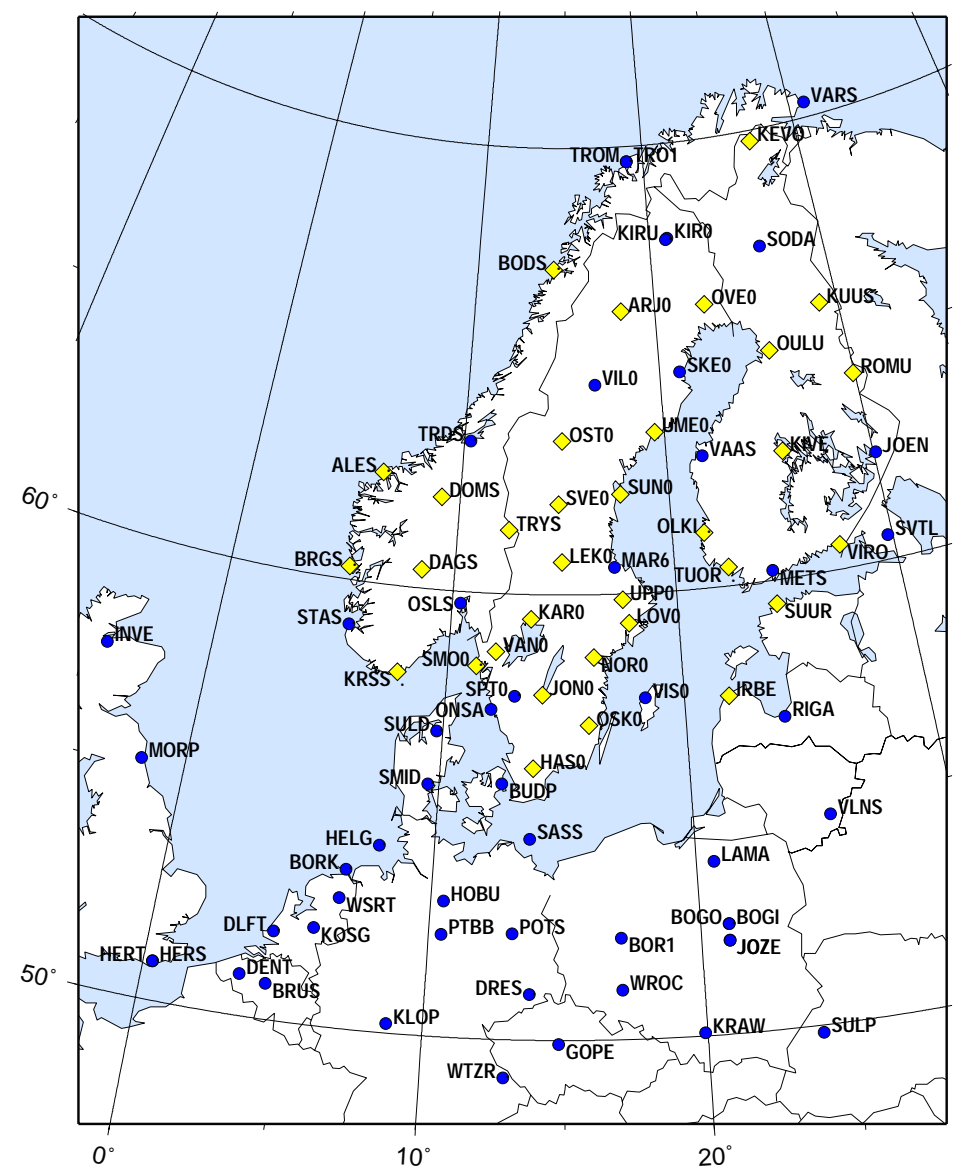

Fig. 1. The extended BIFROST network. Filled dots mark sites available in the public domain through EPN or IGS. Diamonds mark sites in national densifications.

By including stations outside the uplift dome, we may eventually be able to determine the area of the Eurasia tectonic plate where GIA is of significant importance. Depending on the analysis strategy, the additional stations are also needed for the reference frame realization, where the extended BIFROST network is combined with networks from global analysis (see Section 3 below). The locations of the 85 included stations are displayed in Fig 1, where the four-character site identifications are those recognized by the IGS, the EPN, or the national GPS services.

Detailed information on the contributing networks of GNSS stations, included in this study may be found elsewhere. A thorough description of the SWEPOS and FinnRef networks is given in Johansson et al. (2002). Additional information may be found in Koivula et al. (1998), Scherneck et al. (2002), Lidberg et al. (2007), and Lidberg and Lilje (2007).

\section{Data analysis}

\subsection{Analysis of GPS data}

We have re-analyzed all available GPS data collected within the BIFROST effort dating back to August 1993. The last day for analysis is November 4, 2006. Thus, the longest continuous time series span more than 13 years. From 1993 to 1996, only sites in Sweden and some early sites within IGS (the International GNSS Service) were available. In 1996 the EUREF Permanent Network 
(EPN) started, and from about the same time also data from Finland have been included. In Norway, a major upgrade of the SATREF stations was performed in 1998, and we have included available data after this event.

For the analysis we have used the GAMIT/GLOBK software package (Herring et al 2006a-c). Primarily for comparison we have also used the GIPSY/OASIS II software (e.g. Webb and Zumberge, 1993, and Zumberge et al. 1997). The purpose of applying two different software packages to our data is to check for possible systematic effects due to software, or due to implementation of various correction models. The analysis using GIPSY is further presented in Section 4.1.

\subsection{GAMIT/GLOBK analysis}

The GAMIT software applies the so called double differencing approach in a multi-station solution. The results are computed loosely constrained Cartesian coordinates for stations, satellite orbit parameters, as well as their mutual dependencies (variance covariance matrices). Due both to practical matters and for computational efficiency, the analysis of the BIFROST network has been divided into sub-networks. The sub-network division has changed slightly over time while new sites have become available. We have also included some few overlapping sites between the sub-nets. Results from GAMIT are then combined using GLOBK, where also the reference frame is realized. The procedure results in daily estimates of positions for all sites included in the analysis in a well defined reference frame (e.g. ITRF2000 or ITRF2005). From within GLOBK it is also possible to estimate site velocities together with initial site position, by combining several days (and years) of GAMIT analyses and apply constraints for reference frame realization. Such a "GLOBK velocity solution" has been prepared, but is not presented here. The computed station velocities presented in Table 1 have instead been derived from time series analysis of daily position estimates.

Each sub-network has been analyzed using GAMIT in daily sessions. We used a $10^{\circ}$ elevation cut off angle, atmospheric zenith wet delays where estimated every $2^{\text {nd }}$ hour (piece-wise-linear model) applying the Niell mapping functions (Niell 1996) using a priori hydrostatic zenith delays according to Saastamoinen (1972) and standard values for pressure and temperature, together with daily gradient parameters. In the analysis, corrections for antenna phase centre variation (PCV) have been applied according to the models relative to the AOAD/M_T reference antenna model. The phase observations were assigned elevation angle dependent weights determined individually for each station and day from a preliminary solution (e.g. Lidberg et al. 2007 for details). Phase ambiguities were estimated to integers as far as possible using the "LC_HELP" strategy (Herring et al, 2006b). Station motions associated with ocean loading and solid Earth tides were modelled. A priori orbits from the Scripps Orbit and Permanent Array Center (SOPAC), "g-files", were used. The output from GAMIT is so-called quasi-observations including loosely constrained 3-dimensional Cartesian coordinates for each station, 18 orbit parameters for each satellite (of which 15 were estimated in the solution), and 6 earth orientation parameters, including their mutual dependencies.

In the second step of the processing, GLOBK are used for combining our regional sub networks with global networks into single day unconstrained solutions. Finally, constraints that represent the reference frame realization are applied by using a set of globally distributed constraining stations, and solving for translations, rotations and a scale factor, as well as a slight adjustment of the satellite orbit parameters. The result comprises stabilized daily station positions, satellite orbit parameters, and earth orientation parameters (Nikolaidis 2002, Herring et al 2006c)). 


\subsection{Reference frame considerations}

The purpose of our study is to derive a 3D velocity field of the deformation of the crust in Fennoscandia dominated by the ongoing GIA process. In order to resolve the slow and small-scale deformation of the region, a terrestrial reference frame (TRF) consistent over the period of analysis is needed. We also would like to achieve a velocity field that is as independent as possible of any disturbances occurring at a single station. The natural choice is therefore global adaptation to the International Terrestrial Reference Frame (ITRF). We have thus constrained our solution to its latest version, ITRF2005 (Altamimi et al., 2007).

The alternative to a global alignment of our analysis to a reference frame at a superior hierarchy level would be to apply regional constraints. However, in order to follow traditional principles in geodesy when realising a regional reference frame, the area of interest should preferably be surrounded by constraining sites that are not susceptible to the process under examination. In the case of the Fennoscandia GIA process (which is the principal interest of the BIFROST effort) this requirement is almost impossible to fulfill. With its location as a peninsula on the European continent, the post-glacial rebound (PGR) area has the North Sea and the Norwegian Sea to the west, and the Barents Sea to the north. To the east there is a lack of sites at reasonable distance apart from of a number of sites in the wider Moscow region. However, none of these sites provide stable time series for the complete period of this study. Finally, to the south the area between the peripheral subsiding bulge of the PGR and a zone possibly affected by Alpine tectonics is very limited. Also, sediment covers (ironically often glacial deposits) in many cases aggravate stable monumentation, in contrast to the uplift area, where glacially denuded bedrock outcrops are common.

\subsection{TRF realization of the GAMIT/GLOBK analysis}

For the velocity solution from the GAMIT analysis presented in this study, we have combined our regional BIFROST analysis with a global analysis comprising 35 selected sites. The daily combined networks have then been stabilized to the ITRF2005, using 23 sites as candidates for reference frame realization. See Fig. 2.

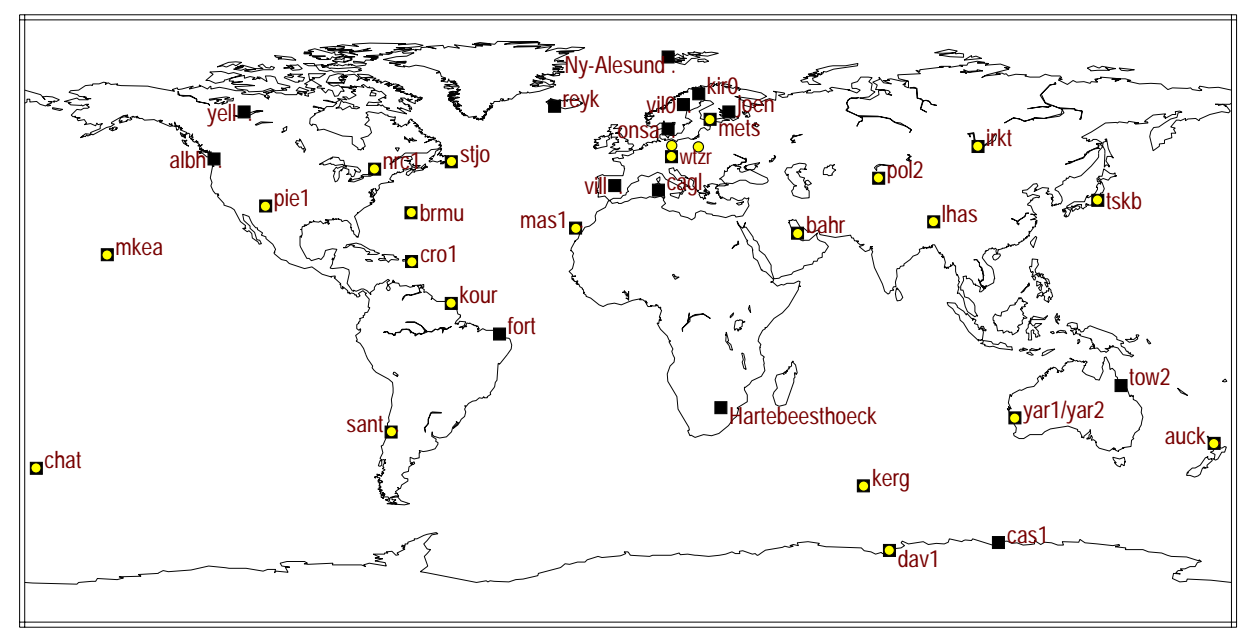

Fig. 2. Network of 35 sites (black squares) and the 23 sites (light circles) used for reference frame realization.

Thus, we have chosen not to follow the strategy applied in Lidberg et al. (2007), where the regional BIFROST solution was combined with global analyzed networks made available by the 
Scripps Orbit and Permanent Array Center (SOPAC 2009 /online/). A preliminary analysis, applying the "BIFROST-SOPAC" combination strategy showed clear non-linear, or bent, shape in the vertical position time series. An apparent partial explanation is the tide model used in the processing (Watson et al 2006). The BIFROST regional network and the SOPAC global network have been analyzed using the IERS1996 tide model (McCarthy 1996), while the IERS2003 model (McCarthy and Petit 2004) was used for the network in Fig 2 (see section 3.3 of Lidberg et al 2008, and section 7 and 8 below).

The early phase of the BIFROST effort, especially up to mid 1996, comprised a period of intensive development and hardware changes at the GPS sites. Of special importance was the test and development of different antenna radomes. This caused several shifts (or jumps) in the position time series and occasionally somewhat spurious features/pertubations with a transient character. The period before August 15, 1996, has therefore been excluded from further analysis.

The outcome of the process described above is a set of daily position estimates for each station, constrained to ITRF2005, where the evolution of the position estimates is dependent on the global velocity field of the ITRF realization. We should therefore be aware of possible contamination in our results, due to shortcomings in the used versions of ITRF (e.g. Altamimi et al 2007, section 8, where the differences between ITRF2000 and ITRF2005 are discussed).

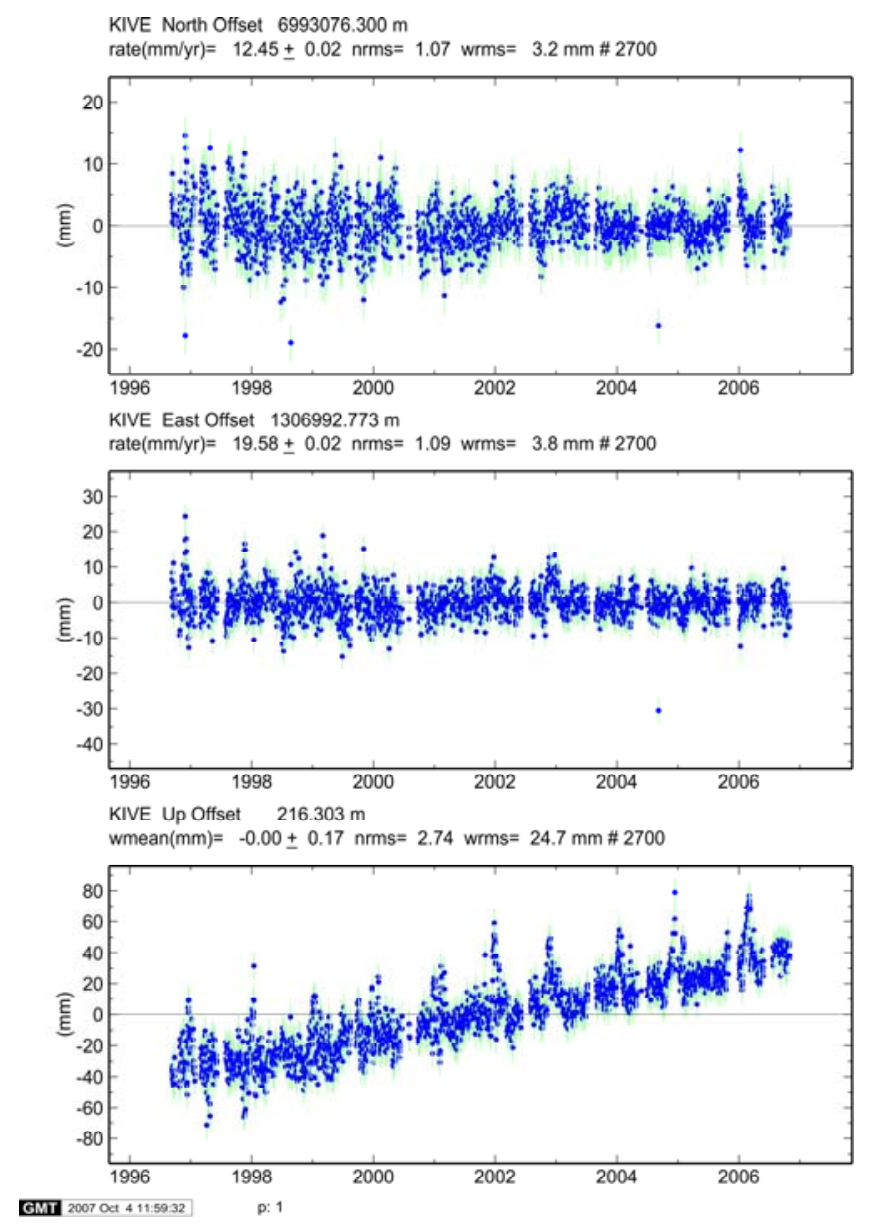

Fig. 3. Example from KIVE of position time series (n,e,u) before editing. The outliers in the vertical component are considered to be caused by snow accumulation on the GPS antenna. Note that a linear trend has been removed from the north and east time series before plotting. 
An example of position time series before editing from KIVE is found in Fig. 3. Note that the north and east components have been de-trended before plotting. We see seasonal variations, in this case especially in the east component. We also see groups of outliers, mainly in the vertical component (e.g. $\sim 2002.0$ in the vertical, $\sim 2003.0$ also in east component). Since this phenomenon has shown to be more pronounced at northern inland sites, and during the winter season, it has been attributed to the accumulation of snow and ice on the radome or antenna (Johansson et al. 2002). This accumulation will cause an additional path delay for the GPS signal, which in combination with the computation strategy may be amplified through the use of atmospheric mapping functions, and result in perturbations in vertical position estimates and occasionally also in the horizontal (Lidberg et al 2007).

\subsection{Time series analysis and data editing}

\subsubsection{Model for estimating station velocities}

Station velocities are estimated from daily estimates of positions in ITRF2005 using an extended linear regression model. When estimating the constant velocity for each component of each station, we simultaneously model seasonal variations by estimating the amplitude of annual and semi-annual sine and cosine functions. The position shifts discussed above are modeled as a step function. Thus six parameters plus one parameter for each shift are estimated for each component. The mathematical expression for the model may be written (Nikolaidis 2002):

$$
\begin{aligned}
& y\left(t_{i}\right)=a+b t_{i}+c \sin \left(2 \pi * t_{i}\right)+d \cos \left(2 \pi * t_{i}\right) \\
& +e \sin \left(4 \pi * t_{i}\right)+f \cos \left(4 \pi * t_{i}\right)+\sum_{j=1}^{n_{g}} g_{j} H\left(t_{i}-T_{g j}\right)+v_{i}
\end{aligned}
$$

where $t_{i}$ are epoch time in years for the daily solutions, $H$ is the Heaviside step function, and $v_{i}$ denotes noise.

\subsubsection{Outlier editing}

The purpose of outlier editing is the removal of erroneous samples in order to prevent them to perturb the estimated station velocities. An additional purpose is to retrieve a clean data set, i.e. one that belongs to a single stochastic distribution; thus the residuals from the deterministic model $\left(v_{i}\right.$ above) can be used to estimate the uncertainty of the derived parameters.

We have used the Tsview software (Herring 2003, MIT 2005 /online/) for data editing and estimation of station velocities. Tsview is a part of the GGMatlab tools which allows interactive viewing and manipulation of GPS velocities and time series with a Matlab-based graphical user interface.

For data editing we have used an automatic outlier function in Tsview with a 5 sigma rejection level. For northern sites with obvious snow problems we have narrowed this to a 3 sigma rejection level, occasionally supported by manual editing. Roughly some 30 data points per year have been removed using this method. Rejecting almost $10 \%$ of the data on the 3 sigma level may be considered much. However, the "snow" samples do not belong to the same group of stochastic samples as the "clean" samples. Thus it could be argued that the percentage of rejected data points is irrelevant. 


\subsection{Accuracy estimates of derived station velocities}

Reliable accuracy estimates of derived station velocities presuppose that the character of the noise of the position time series is known a priori, or that it can be estimated from the noise itself. Assuming a pure white-noise model may result in underestimated velocity errors by a factor of 5 or more (Mao et al. 1999). A common method to handle this is to determine the spectral index and amplitude of the power spectra of the noise using Maximum Likelihood estimation (e.g. Williams 2003 and Williams et al. 2004). An example is the CATS software (Williams 2005 and 2008). In order to present an assessment of the noise characteristics in the GPS time series compatible to what has been performed in other studies, we have employed the CATS software to compute estimates of velocity uncertainties based on estimated spectral index in power-law noise. We run the CATS analysis on position time series after outlier editing performed in Tsview, and using identical epochs for possible shifts. The uncertainty estimates for the three different noise models given in Table 1 are thus based on identical time series and editing results.

We also give uncertainty estimates based on the "realistic sigma"-function of Tsview. In this method the formal uncertainties of derived parameters (assuming white noise) are scaled using a predicted chi-squared-per degree of freedom, assuming a first order Gauss-Markov process (MIT 2005 /online/, Lidberg et al. 2007). Weighted means and a weight for each mean are calculated for consecutive non-overlapping sub-segments of the residual time series, using sub-segments of certain length. The next step is to calculate the normalized $\chi^{2}$ (chi-squared-per degree of freedom) for this sample of means. The process is repeated for longer and longer sub-segment lengths. By studying the increase of the normalized $\chi^{2}$ with increasing length of the sub-segments, the asymptotic value at infinity is predicted. The "realistic sigma" calculation results in estimates of velocity uncertainty usually about 2 to 6 times larger than those based on a white-noise assumption. This is broadly in agreement with findings in other studies (e.g. Scherneck et al. 2002), but somewhat low compared to e.g. Mao et al (1999). The noise properties of BIFROST GPS time series are further investigated using a fractal model in Bergstrand et al. (2005). In the further analysis we use uncertainly estimates based on "realistic sigma".

\section{Results}

The result from the process presented above is a velocity field of the included stations constrained to the ITRF2005 velocity field. A major purpose behind this work, however, is management of geodetic reference frames within the area influenced by the GIA process. Therefore our choice has been to present the results in relation to the stable part of the Eurasian tectonic plate. The computed velocity field is thus transformed (rotated) using the ITRF2005 No-Net-Rotation (NNR) Absolute Rotation Pole for Eurasia. Here we have used values for the rotation pole as presented in Boucher and Altamimi (2008). The resulting station velocities, together with its estimated uncertainties assuming a white nose model, using the "realistic sigma" algorithm, and applying a power law model respectively, are presented in Table 1. The computed velocity field is visualized in Fig. 4. 
Table 1

Computed station velocities and accuracy estimates $(1 \sigma)$ applying three different noise models. Velocities have been transformed using the ITRF2005 absolute rotation pole for Eurasia. Site names are those used by the IGS, EPN or national authorities. Length is difference in years between first and last observation in the position time series.

\begin{tabular}{|c|c|c|c|c|c|c|c|c|c|}
\hline \multirow[t]{2}{*}{ SITE } & \multirow[t]{2}{*}{$\begin{array}{l}\text { Lat } \\
\text { deg }\end{array}$} & \multirow[t]{2}{*}{$\begin{array}{c}\text { Long } \\
\text { deg }\end{array}$} & \multicolumn{3}{|c|}{ Estimated velocity $(\mathrm{mm} / \mathrm{yr})$} & \multicolumn{3}{|c|}{$\begin{array}{c}\text { Estimated uncertainty }(1 \sigma \text { level }) \text { in } \mathrm{mm} / \mathrm{yr} \\
\text { "Realistic sigma" / white noise / power law noise }\end{array}$} & \multirow[t]{2}{*}{$\begin{array}{c}\text { Length } \\
\mathrm{yr}\end{array}$} \\
\hline & & & north & east & up & north & east & up & \\
\hline ALES & 62.476 & 6.199 & 0.83 & -0.76 & 3.72 & $0.09 / 0.03 / 0.12$ & $0.12 / 0.04 / 0.21$ & $0.30 / 0.07 / 0.40$ & 6.8 \\
\hline ARJ0 & 66.318 & 18.125 & 0.30 & -0.30 & 9.11 & $0.10 / 0.02 / 0.14$ & $0.10 / 0.02 / 0.14$ & $0.26 / 0.05 / 0.56$ & 10.2 \\
\hline BODS & 67.275 & 14.358 & 0.66 & -0.84 & 6.39 & $0.09 / 0.03 / 0.14$ & $0.09 / 0.04 / 0.22$ & $0.41 / 0.07 / 0.52$ & 6.5 \\
\hline BOGI & 52.475 & 21.035 & -0.45 & 0.83 & 1.15 & $0.13 / 0.04 / 0.18$ & $0.14 / 0.06 / 0.24$ & $0.30 / 0.13 / 1.56$ & 4.9 \\
\hline BOGO & 52.476 & 21.035 & -0.39 & 0.54 & 0.53 & $0.12 / 0.04 / 0.19$ & $0.11 / 0.05 / 0.21$ & $0.34 / 0.12 / 1.23$ & 6.7 \\
\hline BOR1 & 52.277 & 17.073 & -0.26 & 0.47 & 0.23 & $0.08 / 0.03 / 0.14$ & $0.09 / 0.03 / 0.15$ & $0.27 / 0.07 / 0.62$ & 10.2 \\
\hline BORK & 53.564 & 6.747 & -0.39 & 0.23 & 0.02 & $0.14 / 0.03 / 0.19$ & $0.12 / 0.04 / 0.17$ & $0.38 / 0.09 / 0.54$ & 6.0 \\
\hline BRGS & 60.289 & 5.267 & 0.07 & -0.71 & 3.96 & $0.36 / 0.06 / 0.20$ & $0.45 / 0.08 / 0.30$ & $0.64 / 0.14 / 0.62$ & 6.8 \\
\hline BRUS & 50.798 & 4.359 & 0.29 & 0.20 & 1.78 & $0.37 / 0.04 / 0.28$ & $0.23 / 0.04 / 0.24$ & $0.71 / 0.08 / 0.67$ & 10.2 \\
\hline BUDP & 55.739 & 12.500 & -0.22 & 0.42 & 1.26 & $0.08 / 0.03 / 0.15$ & $0.09 / 0.03 / 0.15$ & $0.36 / 0.07 / 0.64$ & 7.8 \\
\hline DAGS & 60.417 & 8.502 & -0.20 & -0.80 & 7.21 & $0.06 / 0.06 / 0.23$ & $0.08 / 0.07 / 0.32$ & $0.16 / 0.15 / 1.19$ & 4.2 \\
\hline DENT & 50.934 & 3.400 & 0.03 & 1.33 & 0.08 & $0.21 / 0.07 / 0.26$ & $0.31 / 0.09 / 0.31$ & $0.44 / 0.17 / 0.87$ & 4.6 \\
\hline DLFT & 51.986 & 4.388 & -0.09 & 0.01 & 0.26 & $0.17 / 0.03 / 0.18$ & $0.13 / 0.04 / 0.15$ & $0.29 / 0.07 / 0.50$ & 7.7 \\
\hline DOMS & 62.073 & 9.114 & 0.31 & -0.73 & 8.33 & $0.13 / 0.07 / 0.17$ & $0.66 / 0.12 / 0.39$ & $0.50 / 0.18 / 0.86$ & 3.9 \\
\hline DRES & 51.030 & 13.730 & 0.24 & 0.20 & 1.26 & $0.15 / 0.06 / 0.22$ & $0.15 / 0.07 / 0.22$ & $0.51 / 0.15 / 0.93$ & 6.7 \\
\hline GOPE & 49.914 & 14.786 & -0.22 & 0.29 & 1.66 & $0.14 / 0.05 / 0.23$ & $0.16 / 0.06 / 0.22$ & $0.49 / 0.13 / 1.10$ & 7.8 \\
\hline HAS0 & 56.092 & 13.718 & -0.49 & -0.05 & 2.17 & $0.06 / 0.02 / 0.10$ & $0.07 / 0.02 / 0.10$ & $0.31 / 0.04 / 0.46$ & 10.2 \\
\hline HELG & 54.174 & 7.893 & 0.43 & 0.13 & 1.85 & $0.09 / 0.03 / 0.13$ & $0.10 / 0.03 / 0.13$ & $0.38 / 0.07 / 0.44$ & 6.7 \\
\hline HERS & 50.867 & 0.336 & -0.04 & -0.19 & 1.16 & $0.19 / 0.06 / 0.23$ & $0.18 / 0.08 / 0.29$ & $0.32 / 0.12 / 0.65$ & 7.8 \\
\hline HERT & 50.867 & 0.334 & -1.00 & -1.01 & 2.86 & $0.16 / 0.08 / 0.33$ & $0.20 / 0.10 / 0.29$ & $0.36 / 0.18 / 0.91$ & 3.6 \\
\hline $\mathrm{HOBU}$ & 53.051 & 10.476 & -0.26 & 0.78 & 0.72 & $0.07 / 0.03 / 0.14$ & $0.22 / 0.04 / 0.15$ & $0.25 / 0.08 / 0.70$ & 6.4 \\
\hline INVE & 57.486 & 355.781 & 0.36 & -0.31 & 4.00 & $0.12 / 0.07 / 0.25$ & $0.17 / 0.09 / 0.23$ & $0.33 / 0.18 / 0.80$ & 3.6 \\
\hline IRBE & 57.554 & 21.852 & -0.68 & 0.80 & 3.20 & $0.13 / 0.06 / 0.24$ & $0.15 / 0.07 / 0.26$ & $0.44 / 0.16 / 1.23$ & 5.4 \\
\hline JOEN & 62.391 & 30.096 & -1.31 & 0.93 & 4.50 & $0.07 / 0.02 / 0.12$ & $0.09 / 0.02 / 0.12$ & $0.27 / 0.05 / 0.56$ & 10.1 \\
\hline JON0 & 57.745 & 14.060 & -0.90 & 0.03 & 3.57 & $0.06 / 0.02 / 0.10$ & $0.06 / 0.02 / 0.11$ & $0.18 / 0.04 / 0.43$ & 10.2 \\
\hline JOZ2 & 52.098 & 21.032 & -1.04 & 0.90 & 1.11 & $0.13 / 0.05 / 0.20$ & $0.17 / 0.07 / 0.26$ & $0.40 / 0.17 / 1.55$ & 4.0 \\
\hline JOZE & 52.097 & 21.032 & -0.11 & 0.91 & 0.98 & $0.06 / 0.02 / 0.14$ & $0.09 / 0.03 / 0.15$ & $0.18 / 0.07 / 0.57$ & 10.2 \\
\hline KAR0 & 59.444 & 13.506 & -0.59 & -0.17 & 6.33 & $0.06 / 0.02 / 0.11$ & $0.06 / 0.02 / 0.11$ & $0.34 / 0.04 / 0.49$ & 10.2 \\
\hline KEVO & 69.756 & 27.007 & -0.16 & 0.48 & 5.37 & $0.14 / 0.03 / 0.17$ & $0.07 / 0.03 / 0.12$ & $0.49 / 0.06 / 0.63$ & 10.1 \\
\hline KIR0 & 67.878 & 21.060 & 0.15 & 0.08 & 7.72 & $0.11 / 0.02 / 0.13$ & $0.06 / 0.02 / 0.15$ & $0.38 / 0.05 / 0.61$ & 10.2 \\
\hline KIRU & 67.857 & 20.968 & 0.43 & 0.01 & 6.71 & $0.07 / 0.08 / 0.48$ & $0.05 / 0.08 / 0.35$ & $0.56 / 0.16 / 1.00$ & 10.2 \\
\hline KIVE & 62.820 & 25.702 & -1.31 & 1.04 & 7.29 & $0.05 / 0.02 / 0.13$ & $0.05 / 0.02 / 0.13$ & $0.22 / 0.06 / 0.66$ & 10.1 \\
\hline KLOP & 50.220 & 8.730 & 0.23 & -0.38 & 1.08 & $0.17 / 0.05 / 0.21$ & $0.15 / 0.07 / 0.20$ & $0.57 / 0.14 / 0.85$ & 6.7 \\
\hline KOSG & 52.178 & 5.810 & 0.02 & 0.61 & 0.21 & $0.15 / 0.03 / 0.16$ & $0.15 / 0.04 / 0.15$ & $0.37 / 0.08 / 0.47$ & 10.2 \\
\hline KRAW & 50.066 & 19.920 & -0.74 & 0.75 & 0.56 & $0.17 / 0.06 / 0.65$ & $0.16 / 0.08 / 0.31$ & $0.49 / 0.18 / 1.96$ & 3.8 \\
\hline KRSS & 58.083 & 7.907 & -0.10 & -0.15 & 3.27 & $0.06 / 0.03 / 0.12$ & $0.10 / 0.03 / 0.19$ & $0.23 / 0.06 / 0.43$ & 6.8 \\
\hline KUUS & 65.910 & 29.033 & -1.01 & 1.04 & 8.36 & $0.07 / 0.03 / 0.16$ & $0.05 / 0.03 / 0.13$ & $0.25 / 0.07 / 0.88$ & 10.0 \\
\hline LAMA & 53.892 & 20.670 & -0.31 & 0.44 & -0.45 & $0.14 / 0.04 / 0.22$ & $0.13 / 0.05 / 0.21$ & $0.44 / 0.09 / 0.77$ & 10.2 \\
\hline LEK0 & 60.722 & 14.877 & -0.25 & -0.11 & 8.78 & $0.07 / 0.02 / 0.13$ & $0.15 / 0.03 / 0.16$ & $0.15 / 0.06 / 0.62$ & 10.2 \\
\hline
\end{tabular}




\begin{tabular}{|c|c|c|c|c|c|c|c|c|c|}
\hline LOV0 & 59.338 & 17.829 & -0.96 & 0.41 & 6.38 & $0.06 / 0.02 / 0.10$ & $0.04 / 0.02 / 0.12$ & $0.29 / 0.05 / 0.58$ & 10.2 \\
\hline MAR6 & 60.595 & 17.259 & -0.67 & 0.28 & 8.86 & $0.08 / 0.02 / 0.14$ & $0.10 / 0.03 / 0.18$ & $0.24 / 0.06 / 0.65$ & 10.2 \\
\hline METS & 60.217 & 24.395 & -1.28 & 0.90 & 5.21 & $0.05 / 0.02 / 0.13$ & $0.07 / 0.02 / 0.13$ & $0.21 / 0.04 / 0.56$ & 10.2 \\
\hline MORP & 55.213 & 358.315 & 0.17 & 0.67 & 2.88 & $0.44 / 0.10 / 0.60$ & $0.54 / 0.12 / 0.39$ & $0.44 / 0.23 / 1.22$ & 4.0 \\
\hline NOR0 & 58.590 & 16.246 & -1.08 & 0.15 & 5.53 & $0.04 / 0.02 / 0.09$ & $0.08 / 0.02 / 0.11$ & $0.17 / 0.04 / 0.49$ & 10.2 \\
\hline OLKI & 61.240 & 21.473 & -1.22 & 0.92 & 7.66 & $0.04 / 0.02 / 0.11$ & $0.06 / 0.02 / 0.14$ & $0.22 / 0.05 / 0.62$ & 10.1 \\
\hline ONSA & 57.395 & 11.926 & -0.83 & -0.06 & 4.05 & $0.06 / 0.02 / 0.14$ & $0.08 / 0.03 / 0.15$ & $0.27 / 0.06 / 0.44$ & 10.2 \\
\hline OSK0 & 57.066 & 15.997 & -0.70 & 0.08 & 3.19 & $0.05 / 0.02 / 0.10$ & $0.05 / 0.02 / 0.12$ & $0.19 / 0.04 / 0.53$ & 10.2 \\
\hline OSLS & 59.737 & 10.368 & -0.01 & -0.34 & 6.51 & $0.07 / 0.02 / 0.13$ & $0.14 / 0.03 / 0.18$ & $0.19 / 0.06 / 0.47$ & 7.7 \\
\hline OST0 & 63.443 & 14.858 & 0.11 & -0.53 & 9.55 & $0.08 / 0.02 / 0.12$ & $0.08 / 0.02 / 0.12$ & $0.32 / 0.04 / 0.51$ & 10.2 \\
\hline OULU & 65.087 & 25.893 & -0.77 & 1.02 & 9.59 & $0.06 / 0.02 / 0.13$ & $0.04 / 0.02 / 0.12$ & $0.34 / 0.06 / 0.57$ & 10.1 \\
\hline OVE0 & 66.318 & 22.773 & -0.37 & 0.38 & 9.79 & $0.10 / 0.02 / 0.16$ & $0.06 / 0.02 / 0.15$ & $0.34 / 0.05 / 0.58$ & 10.2 \\
\hline POTS & 52.379 & 13.066 & -0.23 & 0.24 & 0.14 & $0.04 / 0.02 / 0.12$ & $0.05 / 0.02 / 0.11$ & $0.26 / 0.05 / 0.48$ & 10.2 \\
\hline РTBB & 52.296 & 10.460 & -0.24 & -0.29 & 0.84 & $0.24 / 0.08 / 0.26$ & $0.36 / 0.10 / 0.29$ & $0.44 / 0.20 / 1.03$ & 6.4 \\
\hline RIGA & 56.949 & 24.059 & -0.66 & 0.39 & 2.23 & $0.07 / 0.03 / 0.15$ & $0.10 / 0.03 / 0.13$ & $0.26 / 0.07 / 0.61$ & 10.2 \\
\hline ROMU & 64.217 & 29.932 & -1.25 & 1.05 & 6.20 & $0.06 / 0.03 / 0.17$ & $0.05 / 0.03 / 0.13$ & $0.25 / 0.07 / 0.88$ & 10.1 \\
\hline SASS & 54.514 & 13.643 & -0.28 & -1.23 & 4.04 & $0.26 / 0.12 / 0.46$ & $0.43 / 0.18 / 0.55$ & $0.83 / 0.42 / 2.41$ & 3.8 \\
\hline SKE0 & 64.879 & 21.048 & -0.02 & 0.02 & 10.95 & $0.09 / 0.02 / 0.12$ & $0.06 / 0.02 / 0.12$ & $0.34 / 0.05 / 0.58$ & 10.2 \\
\hline SMID & 55.641 & 9.559 & -0.03 & 0.18 & 0.43 & $0.19 / 0.06 / 0.19$ & $0.20 / 0.08 / 0.25$ & $0.40 / 0.16 / 0.73$ & 6.6 \\
\hline $\mathrm{SMO} 0$ & 58.353 & 11.218 & -0.46 & -0.88 & 5.18 & $0.10 / 0.05 / 0.17$ & $0.19 / 0.07 / 0.36$ & $0.32 / 0.13 / 0.84$ & 4.0 \\
\hline SODA & 67.421 & 26.389 & -0.46 & 0.69 & 8.53 & $0.07 / 0.02 / 0.16$ & $0.05 / 0.03 / 0.16$ & $0.23 / 0.06 / 0.64$ & 10.1 \\
\hline SPT0 & 57.715 & 12.891 & -0.83 & -0.21 & 4.13 & $0.04 / 0.02 / 0.11$ & $0.03 / 0.02 / 0.12$ & $0.23 / 0.04 / 0.38$ & 10.2 \\
\hline STAS & 59.018 & 5.599 & 0.17 & -0.28 & 2.90 & $0.07 / 0.03 / 0.14$ & $0.12 / 0.04 / 0.19$ & $0.26 / 0.06 / 0.42$ & 7.7 \\
\hline SULD & 56.842 & 9.742 & -0.27 & 0.44 & 1.74 & $0.09 / 0.04 / 0.19$ & $0.12 / 0.06 / 0.22$ & $0.28 / 0.12 / 0.83$ & 7.1 \\
\hline SULP & 49.836 & 24.014 & -0.71 & 0.99 & 0.00 & $0.13 / 0.05 / 0.19$ & $0.15 / 0.06 / 0.22$ & $0.39 / 0.13 / 1.17$ & 5.1 \\
\hline SUN0 & 62.232 & 17.660 & -0.59 & 0.15 & 10.11 & $0.05 / 0.02 / 0.11$ & $0.05 / 0.02 / 0.12$ & $0.29 / 0.04 / 0.53$ & 10.2 \\
\hline SUUR & 59.464 & 24.380 & -0.67 & 1.46 & 4.35 & $0.13 / 0.04 / 0.30$ & $0.12 / 0.04 / 0.28$ & $0.34 / 0.08 / 1.16$ & 8.8 \\
\hline SVE0 & 62.017 & 14.700 & -0.01 & -0.37 & 8.82 & $0.08 / 0.02 / 0.11$ & $0.11 / 0.02 / 0.12$ & $0.22 / 0.04 / 0.49$ & 10.2 \\
\hline SVTL & 60.533 & 29.781 & -1.53 & 1.37 & 3.17 & $0.09 / 0.03 / 0.17$ & $0.10 / 0.04 / 0.18$ & $0.52 / 0.10 / 1.18$ & 9.8 \\
\hline TRDS & 63.371 & 10.319 & 0.74 & -1.14 & 6.19 & $0.08 / 0.03 / 0.13$ & $0.11 / 0.04 / 0.20$ & $0.40 / 0.07 / 0.51$ & 7.7 \\
\hline TRO1 & 69.663 & 18.940 & 1.23 & 1.31 & 4.61 & $0.24 / 0.07 / 0.36$ & $0.31 / 0.10 / 0.34$ & $0.64 / 0.15 / 0.83$ & 7.9 \\
\hline TROM & 69.663 & 18.938 & 0.58 & 0.17 & 4.15 & $0.14 / 0.03 / 0.19$ & $0.13 / 0.03 / 0.18$ & $0.60 / 0.06 / 0.46$ & 10.2 \\
\hline TRYS & 61.423 & 12.382 & 0.30 & -1.44 & 9.54 & $0.13 / 0.07 / 0.26$ & $0.24 / 0.10 / 0.73$ & $0.34 / 0.20 / 1.51$ & 3.8 \\
\hline TUOR & 60.416 & 22.443 & -1.31 & 0.74 & 6.21 & $0.03 / 0.02 / 0.11$ & $0.05 / 0.02 / 0.13$ & $0.20 / 0.05 / 0.58$ & 10.1 \\
\hline UME0 & 63.578 & 19.510 & -0.53 & 0.18 & 11.13 & $0.07 / 0.02 / 0.11$ & $0.04 / 0.02 / 0.11$ & $0.28 / 0.04 / 0.52$ & 10.2 \\
\hline UPP0 & 59.865 & 17.590 & -0.48 & -0.37 & 8.24 & $0.12 / 0.03 / 0.14$ & $0.26 / 0.05 / 0.21$ & $0.31 / 0.11 / 1.36$ & 5.1 \\
\hline VAAS & 62.961 & 21.771 & -1.07 & 0.71 & 9.28 & $0.04 / 0.02 / 0.11$ & $0.04 / 0.02 / 0.12$ & $0.20 / 0.05 / 0.66$ & 10.2 \\
\hline VANO & 58.693 & 12.035 & -0.34 & -0.48 & 4.86 & $0.11 / 0.02 / 0.11$ & $0.08 / 0.02 / 0.13$ & $0.27 / 0.04 / 0.42$ & 10.2 \\
\hline VARS & 70.336 & 31.031 & -0.25 & 0.47 & 5.74 & $0.15 / 0.04 / 0.22$ & $0.09 / 0.04 / 0.20$ & $0.55 / 0.09 / 0.86$ & 7.7 \\
\hline VIL0 & 64.698 & 16.560 & 0.03 & -0.37 & 9.62 & $0.07 / 0.02 / 0.12$ & $0.04 / 0.02 / 0.11$ & $0.21 / 0.04 / 0.50$ & 10.2 \\
\hline VIRO & 60.539 & 27.555 & -1.36 & 0.70 & 3.69 & $0.03 / 0.02 / 0.11$ & $0.05 / 0.02 / 0.14$ & $0.23 / 0.06 / 0.75$ & 10.1 \\
\hline VIS0 & 57.654 & 18.367 & -0.95 & 0.51 & 3.82 & $0.04 / 0.02 / 0.11$ & $0.06 / 0.02 / 0.11$ & $0.16 / 0.05 / 0.59$ & 10.2 \\
\hline VLNS & 54.653 & 25.299 & -0.05 & 0.63 & 0.77 & $0.25 / 0.04 / 0.24$ & $0.17 / 0.05 / 0.22$ & $0.34 / 0.11 / 1.13$ & 8.0 \\
\hline WROC & 51.113 & 17.062 & -0.39 & 0.33 & 1.07 & $0.12 / 0.03 / 0.14$ & $0.16 / 0.04 / 0.18$ & $0.33 / 0.09 / 1.06$ & 6.4 \\
\hline WSRT & 52.915 & 6.605 & 0.63 & 0.00 & 0.39 & $0.09 / 0.02 / 0.13$ & $0.08 / 0.03 / 0.10$ & $0.46 / 0.06 / 0.40$ & 8.3 \\
\hline WTZR & 49.144 & 12.879 & 0.24 & 0.59 & 0.11 & $0.04 / 0.02 / 0.12$ & $0.05 / 0.02 / 0.09$ & $0.18 / 0.04 / 0.45$ & 10.2 \\
\hline
\end{tabular}




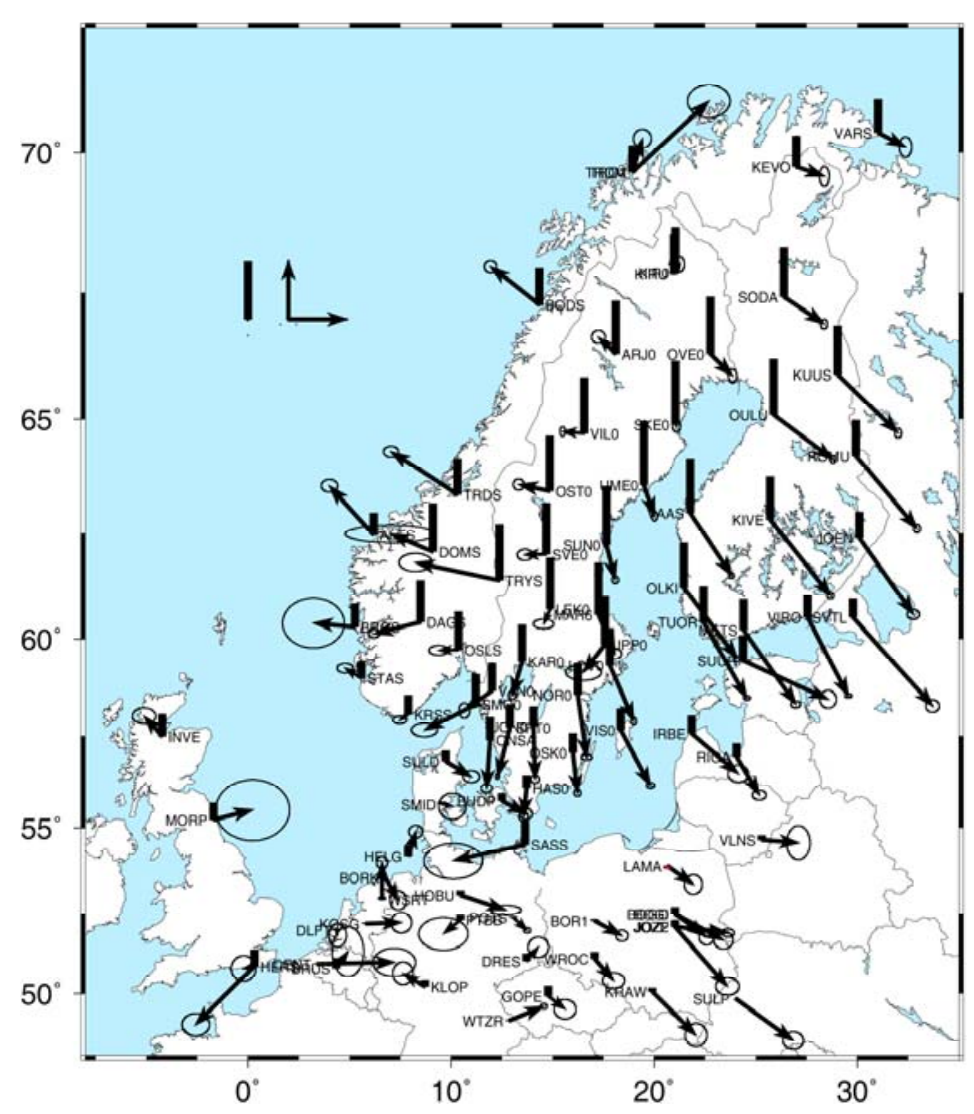

Fig. 4. The velocity field of the GAMIT solution rotated using the ITRF2005 rotation pole for Eurasia. The legend shows $10 \mathrm{~mm} / \mathrm{yr}$ in the vertical and $1 \mathrm{~mm} / \mathrm{yr}$ in horizontal components.

\subsection{Intercomparison of GAMIT and GIPSY solutions}

The GIPSY software is principally different from GAMIT/GLOBK. A Kálmán filter approach is applied to solve all parameters (satellite and receiver clock parameters, possibly satellite orbit parameters, etc.) rather than reducing their influence on estimated station positions by differencing techniques. This "zero differencing" approach for GPS analysis has allowed the development of the well-known precise point positioning (PPP) technique commonly applied in GPS analysis using the GIPSY software (Zumberge et al. 1997).

In the GIPSY analysis presented here, the PPP technique has been employed in a non-fiducial approach, and using satellite orbit and clock products from the Jet Propulsion Laboratory (JPL). In a second step of the analysis, we have also resolved the phase ambiguities to integers (using Ambigon2). The daily no-fiducial solutions have then been transformed to the ITRF2005 reference frame, using daily transformation files (x-files) provided by JPL. The analysis setup regarding elevation cut-off angle, mapping function etc. is similar to the GAMIT setup (section 3.2 above) with the exception that no elevation dependent weighting has been used in the GIPSY analysis. To derive station velocities from the daily position estimates (same time period as for GAMIT/GLOBK, but reduced number of stations) we have again used the "tsview" tool.

Differences between this GIPSY solution and the GAMIT solution above are shown in Fig. 5. The GIPSY solution has been rotated to best fit the horizontal velocities (no corrections applied in the vertical component) of the GAMIT solution. The resulting residuals show a mean value close to zero $(-0.06 \mathrm{~mm} / \mathrm{yr}$ in the vertical), and standard deviation of $(0.14,0.15,0.24) \mathrm{mm} / \mathrm{yr}$ for the $(\mathrm{n}, \mathrm{e}, \mathrm{u})$ 
components respectively. The good agreement indicates that there are no significant differences between results obtained using the two different software packages.

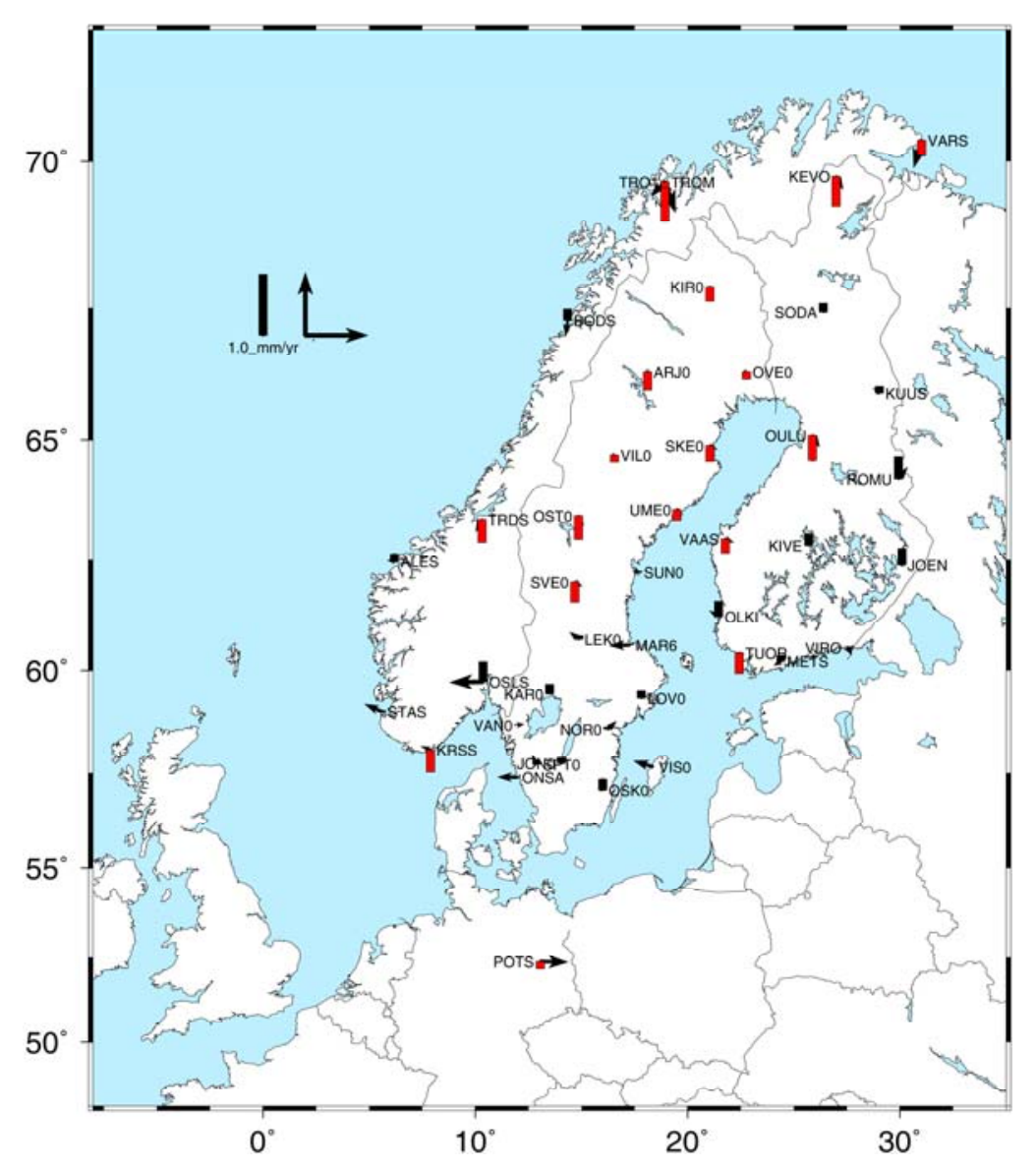

Fig. 5. The differences between station velocities from the new GIPSY solution and the GAMIT solution. (GIPSY minus GAMIT). Black vertical bars are positive and red/grey bars are negative. The GIPSY solution has been rotated to best fit the horizontal velocities of the GAMIT solution. The legend shows $1 \mathrm{~mm} / \mathrm{yr}$ in vertical and horizontal components.

\section{Revised rheology parameters in the GIA model}

For evaluation purposes we compare our GPS derived station velocities with predictions from a geophysical GIA model. We choose optimal Earth model parameters based on the data-model fit presented in Lidberg et al (2007), in which the data were constrained to ITRF2000. The results of that analysis, summarised in Fig. 6, led to an optimal model that is defined by a $120 \mathrm{~km}$ thick lithosphere, an upper mantle viscosity $\left(v_{u m}\right)$ of $5 \times 10^{\wedge} 20$ Pas and a lower mantle viscosity ( $\left.v_{\mathrm{lm}}\right)$ of 5 $\times 10^{\wedge} 21$ Pas. (For comparison, the optimum values obtained for the older GPS solution (Johansson et al. 2002) were, respectively, $120 \mathrm{~km}, 8 \times 10^{\wedge} 20$ Pas and $10^{\wedge} 22$ Pas.) Even though the GIA model considered here is not directly tuned to the station velocities in Table 1, some tests based on a number of preliminary GPS velocity solutions (adjusted to both ITRF2000 and to ITRF2005) indicate that this set of Earth model parameters is close to optimum for the data presented here. 

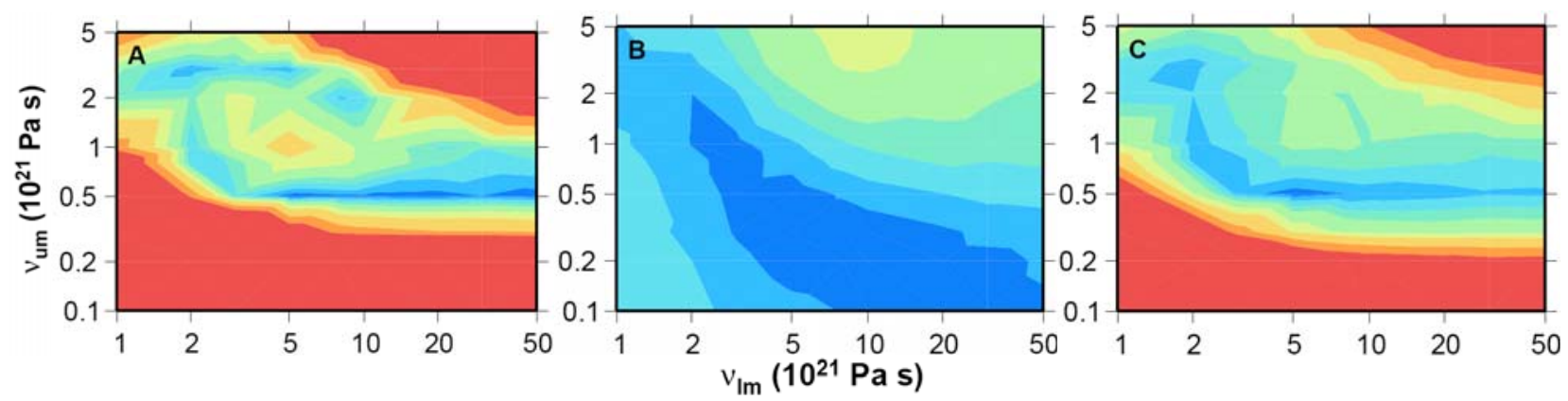

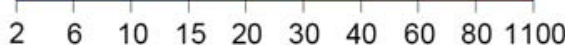

Fig. 6. $\chi 2$ misfit per degree of freedom (d.o.f.) between GPS-derived crustal velocities and numerical GIA predictions based on a suite of Earth models and the ice model of Lambeck et al. (1998a). Misfit is shown as a function of vum and Vlm for the (A) radial, (B) horizontal, and (C) full 3D velocity components respectively. The lithospheric thickness of the Earth models was fixed to $120 \mathrm{~km}$.

\section{Evaluation of observed site velocities}

In Fig. 7A we show the horizontal station velocities according to the GIA prediction model together with the observed velocities presented above. The GPS station velocities as well as the GIA model velocities have been slightly rotated to have zero velocity in "continental Europe" and at the point of maximum land uplift. The motivation for this is that (a) the GIA model contains a global net rotation (a polar motion component) due to contemporary mass redistribution and loading in the global ocean (Milne and Mitrovica 1998); (b) the GIA produces far-field motion due to the Laurentide ice sheet, which is rather uniform in the Fennoscandia region, i.e. to a large part indistinguishable from a rigid rotation of the Fennoscandian network.

In principle, the scale in ITRF2000 is derived from observations using VLBI (Very Long Baseline Interferometry) and SLR/LLR (Satellite and Lunar Laser Ranging), while only VLBI have been used to determine the scale in ITRF2005 (Altamimi et al., 2007). Because SLR is the only technique able to sense the earth centre of mass, with accuracy comparable to the positioning accuracies achievable from GPS or VLBI, the earth centre of mass is entirely derived from SLR in both the ITRF2000 and the ITRF2005. These considerations about scale and earth centre of mass are also valid for possible changes in scale, or stability in the determination of the centre of mass of the earth in the different realizations of the ITRF. E.g. instability in centre of mass would map at a 1:1 ratio into derived station velocities, while a possible instability in scale at the $0.1 \mathrm{ppb} / \mathrm{yr}$ could contaminate the derived vertical velocity by about $0.6 \mathrm{~mm} / \mathrm{yr}$.

The problem described is actually what we face with the two most recent versions of ITRF. In the parameters of the 14 parameter Helmert transformation from ITRF2005 to ITRF2000, the change in origin is $-1.8 \mathrm{~mm} / \mathrm{yr}$ along the Z-axis, and the rate of scale is $0.08 \mathrm{ppb} / \mathrm{yr}$ (Table 6 , Altamimi et al., (2007)). At a site at latitude $60^{\circ} \mathrm{N}$, centrally located within the BIFROST network, this would imply a difference in vertical velocity of $-1.1 \mathrm{~mm} / \mathrm{yr}$ (and $-0.9 \mathrm{~mm} / \mathrm{yr}$ in north direction). Limitations in corrent methodology for ITRF and a proposed alternative approach are discussed in Argus (2007). The alternative approach is based on the centre of mass of the solid earth (CE) rather that centre of mass of the earth system (CM). In the paper is given also values for transformation from ITRF2000 (and ITRF2005) to the alternative frame. 
According to the discussion above we may not trust the superior TRF to the sub-mm/yr level. Therefore we have transformed (translation and rotation) the observed velocities (this and further analysis is based on the GAMIT/GLOBK solution given in Table 1) to best fit the GIA prediction model at our sites in Finland and Sweden with the longest observation time span. The RMS of the velocity residuals of this fit are $(0.32,0.17,0.35) \mathrm{mm} / \mathrm{yr}$ for the $(\mathrm{n}, \mathrm{e}, \mathrm{u})$ components respectively. Before the fit, there was a $0.9 \mathrm{~mm} / \mathrm{yr}$ bias in the vertical (GPS larger than the GIA model). The residuals are given in Fig 7B. Compared to Lidberg et al (2007), where GPS-derived velocities were compared to the GIA prediction model of Milne et al (2001) resulting in a bias of $0.3 \mathrm{~mm} / \mathrm{yr}$ and standard deviation of $0.9 \mathrm{~mm} / \mathrm{yr}$, we have now achieve a considerable improvement.
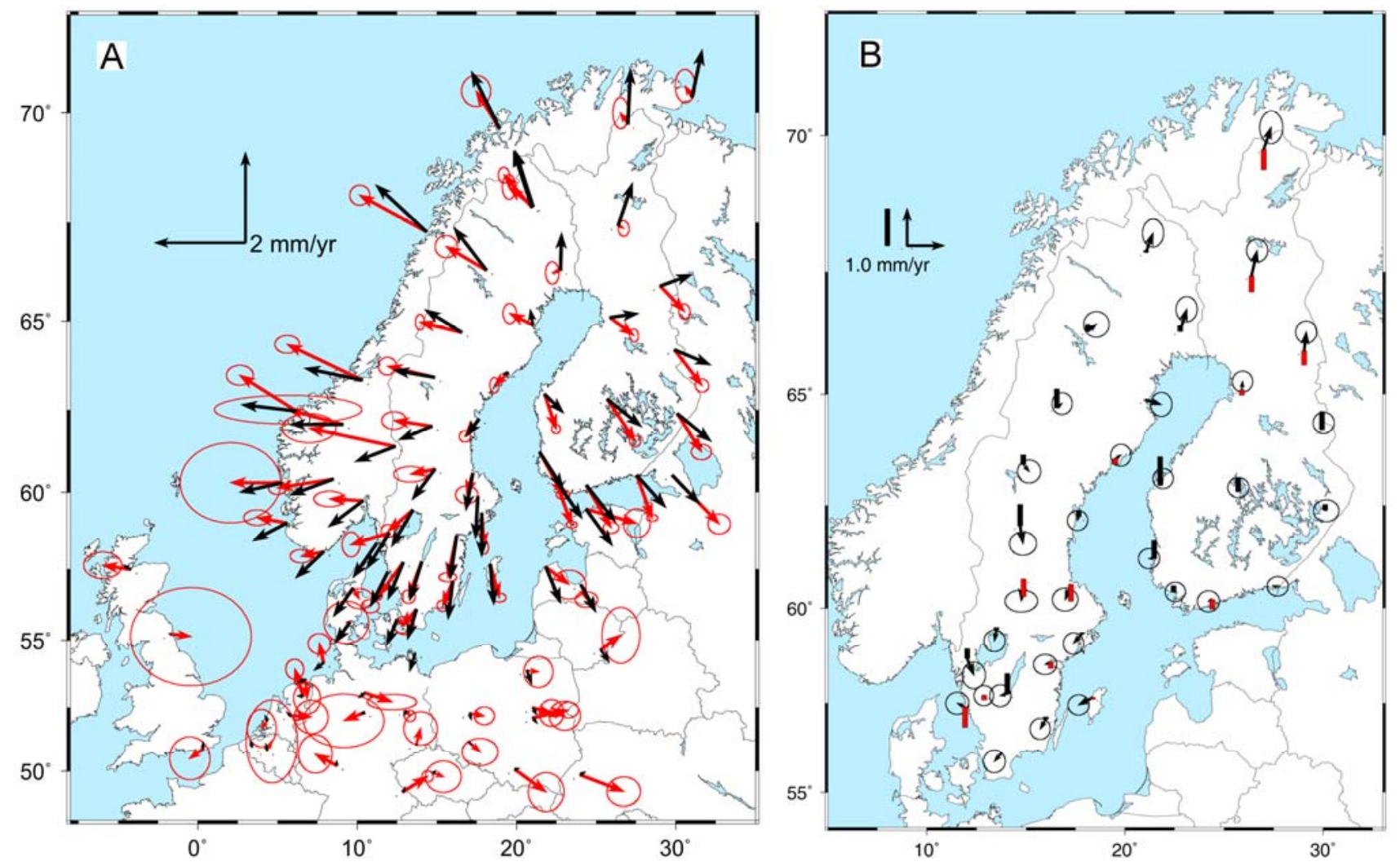

Fig. 7.Left (7A): Horizontal station velocities from the revised GIA model, rotated to give zero velocities in "continental Europe" and at maximum land uplift (black arrows), together with observed GPS-derived velocities rotated to best fit the (rotated) GIA predictions (red or grey arrows with 95\% probability ellipses). Right (7B): Residuals after fit between the revised GIA model and the GPS-derived velocities in Finland and Sweden. See text.

In Fig. 8 are shown vertical rates from the new GAMIT solution, transformed (rotated and translated) to best fit the new GIA model (denoted "This paper"), the solution presented in (Lidberg et al. 2007) (denoted "J Geod"), and the revised GIA model. Finally we compare our results with the vertical velocities presented in Ekman (1998). These are based on apparent land uplift of the crust relative to the sea level observed at tide-gauges during the 100 years period 1892-1991 as presented in Ekman (1996) where the inland is densified by repeated levellings, an eustatic sea level rise of 1.2 $\mathrm{mm} / \mathrm{yr}$ has been applied, and the rise of the geoid (relative to the ellipsoid) is based on computations presented in Ekman and Mäkinen (1996). From a thorough discussion in the paper on the reliability, the standard errors are estimated to between $0.3-0.5 \mathrm{~mm} / \mathrm{yr}$, where the larger values apply to inland stations or stations with a weak connection (from repeated levelling) to the nearest tide-gauge. 


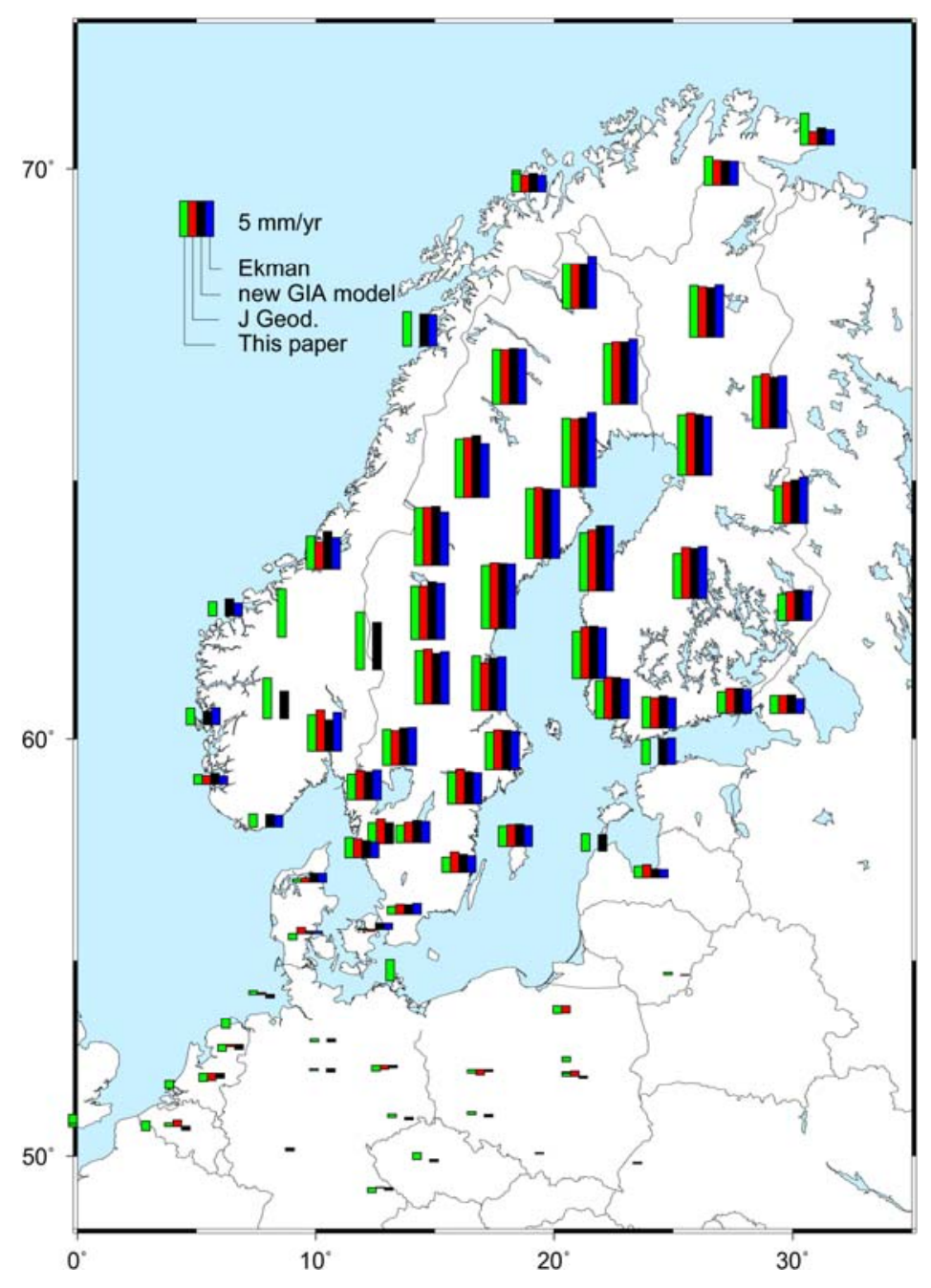

Fig. 8.Vertical velocities (from left to right); from table 1 transformed to the revised GIA model, the solution presented in (Lidberg et al. 2007), the revised GIA model (black), and values presented by Ekman (1998).

\section{Possible limitations in the velocity solution}

Possible limitations in the reference frame realisation have been discussed in section 6 , and comparisons in results between using ITRF2000 or ITRF2005 was given in Lidberg et al. (2008). Consequently we must be aware of a possible bias in the velocities presented in Table 1 due to limitations in the reference frame realisation.

Lidberg et al. (2008) also discussed comprehensively conspicuous non-linear trends in the position time series, especially for sites at high latitude. There are a number of candidate causes for this nonlinearity behaviour, and in particular the use of different tide models was widely discussed (in the solution presented in this paper in Table 1, the IERS 1996 solid earth tide model was used for the BIFROST network (Fig.1), while the IERS 2003 solid earth tide model was used for the global network (Fig. 2)). See further Watson et al. (2006) as to how the choice of tide model may influence derived station velocities. Further, a specific study on aliased tidal signatures in GPS time series are 
presented in Penna and Stewart (2003), and the propagation of un-modelled systematic errors into coordinate time series is investigated in Stewart et al. (2005).

Other candidates to explain non-linearity in position time series may be side effects from the succession of GPS satellite block types (Ge et al. 2005), and contributions from higher order ionospheric terms (Kedar et al. 2003) which have not been corrected for here. Corrections for atmospheric loading have not been taken into account in this solution. Including this at the observation level will improve the analysis (e.g. Tregoning and van Dam 2005). New mapping functions are now available (e.g. Tesmer et al. 2007), and GNSS antenna properties should be modeled according to absolute calibrated antenna phase center variations (PCVs). It may also be noted that some of the possible improvements may be difficult to implement in practice to get full advantage of them. E.g. the PCV determined in absolute antenna calibration may be valid for an isolated antenna, but these properties may change due to electro-magnetic coupling and scattering effects when the antenna is attached to its foundation (Granström 2006).

Special attention ought to be directed to the mix of perturbations originating in the succession of GPS satellite block types, antenna PCV models (relative or absolute), limitations in atmospheric mapping function, and sites at high latitudes where satellites is no more visible up to zenith elevation. This complicated budget of systematic errors with its nonstationary character is likely to result in systematic changes of estimated vertical position over time.

\section{Preliminary sparse test on improved GNSS analysis}

We have performed a "sparse analysis" including a small number of stations in the BIFROST network taking observations only at a ten day interval. We have used the IERS 2003 tide model, absolutely calibrated GPS antenna models (igs05.atx), and the global troposphere mapping function GMF (Boehm et al 2006). The regionally decimated BIFROST network has been combined with reprocessed global products (so called GAMIT h-files) that SOPAC has recently made available (SOPAC 2009 /online/).

Plots of the time series of the vertical position from the Swedish station Vilhelmina (VIL0), located at $64.7^{\circ} \mathrm{N}$, are given in Fig 9. The three plots are from three different solutions computed using the GAMIT/GLOBK software package, and applying a global constraint to the ITRF2005 reference frame. Raw plots are given where just a linear trend has been removed, but no data editing or modeling of seasonal signals have been applied. In the top plot of Fig 9, the regional BIFROST analysis is combined with the global SOPAC analysis applying the "old" analysis strategy (IERS1996 tide model, antenna PCV models relative to AOAD/M_T, NMF mapping function etc. e.g. Lidberg et al. 2008). The middle plot is from the analysis and results presented in this paper. I.e. the regional analysis is the same as "top" but we combined with the global network in Fig 2, computed using the IERS2003 tide model (see section 3.4). The plot in the bottom of Fig 9 is from the sparse analysis.

Note that the last analysis is performed only every $10^{\text {th }}$ day compared to every day for top and middle plot of Fig 9. Nevertheless, we see that the non-linear trend (sometimes denoted "bananashape") is highly reduced in the bottom plot. This is visible also at other sites.

In order to quantify the non-linear component of the vertical position time series, we have in this small investigation adapted a second order polynomial to the observations:

$$
y\left(t_{i}\right)=a+\dot{h}\left(t_{i}-t_{0}\right)+\ddot{h}\left(t_{i}-t_{0}\right)^{2}+v_{i}
$$

where $t_{i}$ are epoch time in years for the position estimate and $t_{0}$ is chosen as epoch 2002.0, and $v_{i}$ denotes noise. 
The value of the second order term, together with its uncertainty estimate, is given in Table 2 for the vertical position time series of VIL0, from the three different solutions given in Fig. 9. It is clear that the "bending" of the time series is highly reduced for the new analysis strategy discussed above and presented in the bottom plot of Fig. 9.

Table 2

Estimated value of the "bending" term of eq. 2, together with its estimated uncertainty, for the three vertical position time series of VIL0 shown in Fig 9.

\begin{tabular}{lccc}
\hline $\begin{array}{l}\text { Time series in Fig. } 9 \\
\text { See text. }\end{array}$ & $\begin{array}{c}\sigma_{0} \text { - standard error of } \\
\text { single sample according } \\
\text { to white nose model } \\
(\mathrm{mm})\end{array}$ & $\begin{array}{c}\text { The second order term in } \\
\text { eq. } 2, \ddot{h} . \\
\left(\mathrm{mm} / \mathrm{yr}^{2}\right)\end{array}$ & $\begin{array}{c}\text { Standard error } \sigma_{\ddot{h}} \text { of estimated } \\
\ddot{h} \text {, using white noise model. } \\
\left(\mathrm{mm} / \mathrm{yr}^{2}\right)\end{array}$ \\
\hline VIL0 a, top & 5.4 & 0.31 & 0.013 \\
VIL0 b, middle & 7.3 & 0.22 & 0.017 \\
VIL0 c, bottom & 6.2 & 0.12 & 0.031 \\
\hline
\end{tabular}

The non-linear or bended shape (or possible change of rate by about mid 2003) of vertical position time series discussed here is visible in most of our high latitude sites (possibly above $55^{\circ} \mathrm{N}$ ) and seems to be more pronounced towards the north. We also stress that long uninterrupted time series are needed to see this phenomenon. Studying time series plots from several sites, based on different analysis strategies, the preliminary conclusion is therefore that a bent vertical time series, or possible increase in vertical velocity starting about 2002-2004, may partly be contaminated by limitations in the strategy for the GPS analysis. This should be considered also in other projects, e.g. while using GPS for studying an increase in vertical velocity of the crust at high latitude locations, in order to detect change in glacier ice melt possible due to climate change.

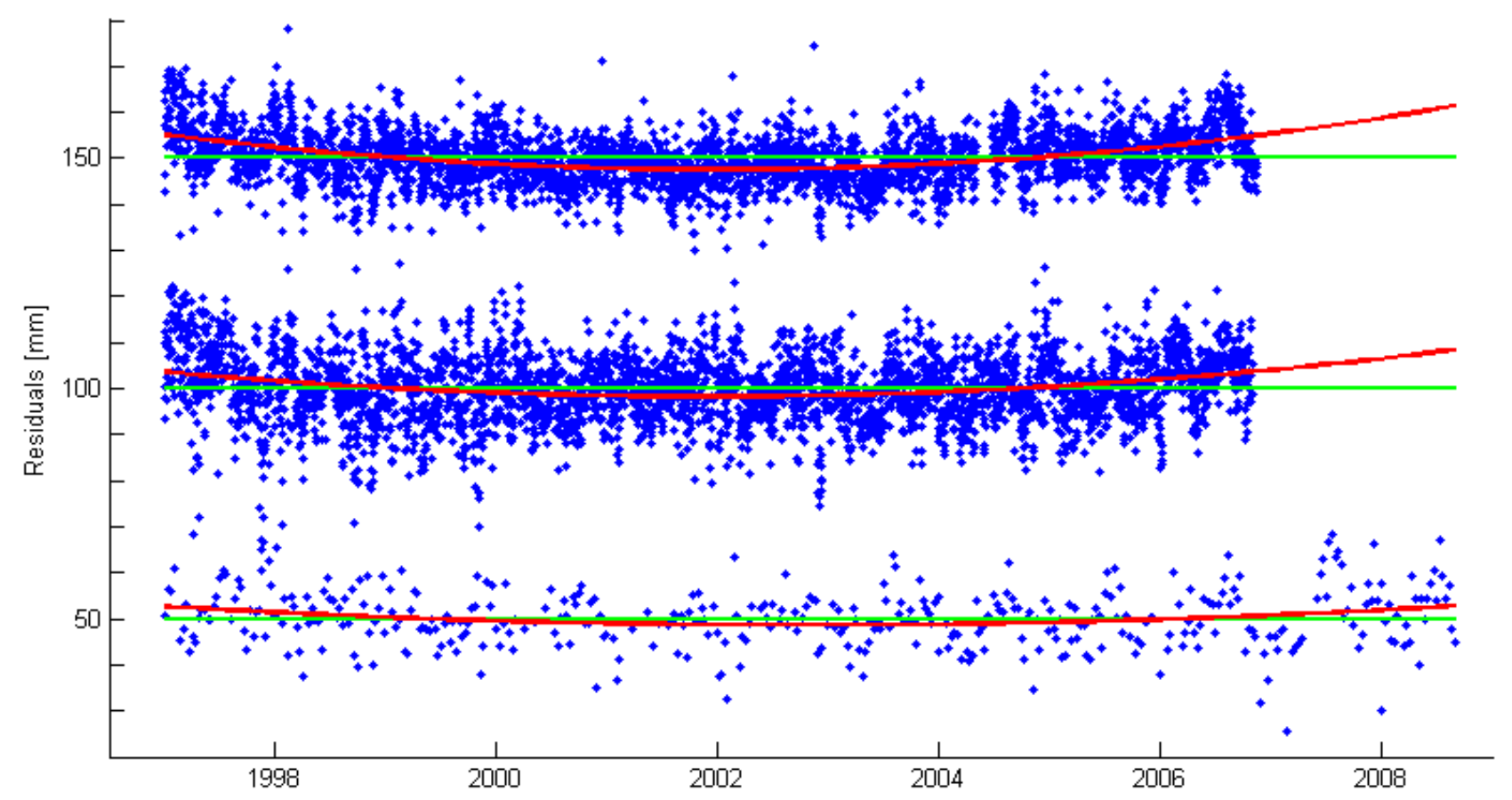

Fig. 9. Time series plot of the vertical position (linear trend removed) for the station Vilhelmina (VIL0) for three different solutions, computed using GAMIT/GLOBK software package. Top: regional BIFROST combined with global SOPAC analysis using "old” analysis strategy. Middle: this paper, i.e. the same BIFROST analysis as "top", but 
combined with the global network in Fig. 2. Bottom: the sparse test analysis presented in this section computed using "absolute" antenna calibration models.

\section{Conclusions}

We have presented numerical values on crustal motions in the Fennoscandia area, subject to GIA induced motion. These velocities, computed from permanently operating GPS stations, have been evaluated internally by applying advanced models for the noise characteristics. The presented velocity solution is further checked by applying two different software packages, GAMIT and GIPSY, and the result agree on the average at the $0.2 \mathrm{~mm} / \mathrm{yr}$ level. We also present revised rheology parameters in the GIA model. The agreement between the revised GIA prediction model and GPSderived station velocities $(0.4 \mathrm{~mm} / \mathrm{yr}$ for the best sites) shows booth good performance of the GIA model as well as good reliability of the GPS velocities.

However, we stress the difference (also reported elsewhere) between velocities from the two latest versions of the International Terrestrial reference Frame, ITRF2000 and ITRF2005. This difference indicates an uncertainty in absolute vertical velocity possibly at the $1 \mathrm{~mm} / \mathrm{yr}$ level due to reference frame realisation. We have further discussed possible limitations in applied analysis strategy of the GPS observations. The small investigation in section 8 indicates possibility for considerable improvements for future re-analysis of the BIFROST network.

\section{Acknowledgements}

We thank those who operate permanent GNSS stations and make their data available for this kind of studies, for this particular study the Nordic and Baltic countries are acknowledged. We are grateful to SOPAC for making quasi observations from global networks public available, and MIT for the GAMIT/GLOBK software. Maps in this paper were generated using the generic mapping tools (GMT) (Wessel and Smith 1998). Finally we thank Matt King and one anonymous reviewer for valuable comments and suggestions which have improved the manuscript.

\section{References}

Altamimi Z, Sillard P, Boucher C (2002) ITRF 2000: A New Release of the International Terrestrial Reference Frame for earth Science Applications, J Geophys. Res., 107(B10),2214, doi:10.1029/2001JB000561.

Altamimi, Z., X. Collilieux, J. Legrand, B. Garayt and C. Boucher, (2007). ITRF2005: A new release of the International Terrestrial Reference Frame based on time series of station positions and Earth Orientation Parameters. J. Geophys. Res., 112, B09401, doi: 10.1029/2007 JB004949.

Argus D (2007) Defining the translational velocity of the reference frame of Earth, Geophys. J. Int., 169, 830-838. doi: 10.1111/j.1365-246X.2007.03344.X

Bergstrand S, H.-G. Scherneck, M. Lidberg, J.M. Johansson (2005). BIFROST: Noise properties of GPS time series. In Proc of International Assosiation of geodesy Symposia 'Understanding a Dynamic Planet with Geodetic and Oceanographic Tools’. Tregoning P Rizos C (eds.) Vol. 130, Springer Berlin Heidelberg New York. pp 123-130. ISBN: 978-3-540-49349-5.

Boehm J, Niell A, Tregoning P, Schuh H (2006) The global mapping function (GMF): a new empirical mapping function based on data from numerical weather model data. Geophys Res lett 33:L07304. DOI:10.1029/2005GL025546.

Boucher C, Altamimi Z (2008) Memo: Specification for reference frame fixing in the analysis of a EUREF GPS campaign Version 7 : 24-10-2008. http://etrs89.ensg.ign.fr/memo-V7.pdf . (cited January 2009)

Ekman M. (1996): A consistent map of the postglacial uplift of Fennoscandia, Terra Nova, 8, 158-165.

Ekman M, Mäkinen J (1996) Recent postglacial rebound, gravity change and mantle flow in Fennoscandia. Geophys. J. Int. 126, 229-234. 
Ekman M (1998) Postglacial uplift rates for reducing vertical positions in geodetic reference systems. In proceedings of the General Assembly of the Nordic Geodetic Commission, May 25-29, 1998, Edited by B. Jonsson, ISSN 02805731 LMV-rapport 1999.12.

EUREF (2007) [online] EUREF Permanent Network. http://www.epncb.oma.be/, (cited Jan 2009)

FGI (2007) [online] The Finnish Permanent GPS Network (FinnRef). http://www.fgi.fi/asemat/gps_eng.php, (cited Jan 2009)

Ge M, Gendt G, Dick G, Zhang F P, Reigber C (2005) Impact of GPS satellite antenna offsets on scale changes in global network solutions, Geophys Res Lett 32 L06310 doi:10.1029/2004GL022224.

Granström C. (2006). Site-Dependent Effects in High-Accuracy Applications of GNSS. Licentiate thesis, Technical report no 13L, Department of Radio and Space Science, Chalmers University of Technology, Sweden.

Herring T A (2003) MATLAB Tools for viewing GPS velocities and time series. GPS solutions 7:194-199.

Herring T. A., R. W. King, S.C. McClusky (2006a), Introduction to GAMIT/GLOBK, Release 10.3. Department of Earth, Atmosphereic and Planetary Sciences, Mass. Inst. of Technol., http://chandler.mit.edu/ simon/gtgk/Intro_GG_10.3.pdf, (cited Apr 2007)

Herring T. A., R. W. King, S.C. McClusky (2006b), GAMIT reference manual, Release 10.3. Department of Earth, Atmosphereic and Planetary Sciences, Mass. Inst. of Technol., http://chandler.mit.edu/ simon/gtgk/GAMIT_Ref_10.3.pdf, (cited Apr 2007)

Herring T. A., R. W. King, S.C. McClusky (2006c), GLOBK reference manual, Release 10.3. Department of Earth, Atmosphereic and Planetary Sciences, Mass. Inst. of Technol., http://chandler.mit.edu/ simon/gtgk/GLOBK_Ref_10.3.pdf, (cited Apr 2007)

Johansson J M, Davis JL, Scherneck H-G, Milne GA, Vermeer M, Mitrovica JX, Bennett RA, Jonsson B, Elgered G, Elósegui P, Koivula H, Poutanen M, Rönnäng BO, Shapiro II (2002) Continous GPS measurements of postglacial adjustment in Fennoscandia 1. Geodetic results. J Geophys Res, vol. 107, no. B8, 10.1029/2001B000400.

Kedar S, Hajj G A, Wilson B D, Heflin M B (2003) The effect of the second order GPS ionospheric correction on receiver positions, Geophys Res Lett 30(16) 1829 doi:10.1029/2003GL017639.

Koivula H, Ollikainen M, Poutanen M, (1998) Use of the Finnish permanent GPS network (FinnNet) in regional GPS campaigns, in Advances in Positioning and Reference Frames, Int Assoc Geod Symp., vol. 118, edited by F. K. Brunner, pp137-142, Springer-Verlag, New York.

Lambeck K, Smither C, Johnston P (1998) Sea-level change, glacial rebound, and mantle viscosity for northern Europe. Geophys. J. Int., 134, 102-144.

Lidberg M, J.M. Johansson, H.-G. Scherneck, J.L. Davis (2007). An improved and extended GPS derived velocity field for the glacial isostatic adjustment in Fennoscandia. Journal of Geodesy, 81 (3), pp 213-230. doi: 10.1007/s00190006-0102-4.

Lidberg M, M. Lilje (2007). Evaluation of monument stability in the SWEPOS GNSS network using terrestrial geodetic methods - up to 2003. LMV-rapport 2007:10. ISSN 280-5731.

http://www.lantmateriet.se/upload/filer/kartor/geodesi_gps_och_detaljmatning/Rapporter-Publikationer/LMVrapporter/LMV-rapport_Swepos_pelare till_PDF_2007 h.pdf (sited Jan 2009)

Lidberg M, J.M. Johansson, H.-G. Scherneck, G. A. Milne, J.L. Davis (2008). New results based on reprocessing of 13 years continuous GPS of the Fennoscandia GIA process from BIFROST. In M. G. Sideris (ed.) "Observing our Changing Earth", Proceedings of the 2007 IAG general assembly, Perugia Italy, July, 2-13. International Association of Geodesy Symposia Vol. 133, pg 557ff, Springer.

McCarthy D (1996) IERS Conventions (1996). IERS Technical Note 21. http://maia.usno.navy.mil/conventions.html, (cited July 2009)

McCarthy D, Petit G (2004) IERS Conventions (2003). IERS Technical Note 32, Verlag des Bundesamts für Kartographie und Geodsie, Frankfurt am Main, Germany, http://tai.bipm.org/iers/conv2003/conv2003.html, (cited July 2009)

Mao A, Harrison CGA, Dixon TH (1999) Noise in GPS coordinate time series. J Geophys Res 104:2797-2816.

Milne, G.A., Mitrovica, J.X., Davis, J.L., 1999. Near-field hydroisostasy: the implementation of a revised sea-level equation. Geophysical Journal International 139, 464-482.

Milne GA, Davis JL, Mitrovica JX, Scherneck H-G, Johansson JM, Vermeer M, Koivula H (2001) Space-Geodetic Constraints on Blacial Isostatic Adjustments in Fennoscandia. Science 291, 2381-2385.

Milne GA, Mitrovica JX (1998) Postglacial sea-level change on a rotating earth, Geophys. J. Int., 133, 1-19.

Milne GA, Mitrovica JX, Scherneck H-G, Davis JL, Johansson JM, Koivula H, Vermeer M, 2004. Continuous GPS measurements of postglacial adjustment in Fennoscandia: 2. Modeling results. J. Geophys. Res. 109, B02412, doi:10.1029/2003JB002619.

MIT (2005) [online] GAMIT/GLOBK Matlab Tools. http://geoweb.mit.edu/ tah/GGMatlab/, (cited June 2005)

Niell AE (1996) Global mapping functions for the atmosphere delay at radio wavelengths, Jour Geophys. Res. 101, 3228-3246. 
Nikolaidis RM (2002) Observation of Geodetic and Seismic Deformation with the Global Positioning System, Ph.D. Thesis, University of California, San Diego. http://sopac.ucsd.edu/input/processing/pubs/nikoThesis.pdf (cited January 2009)

Penna N T, Stewart M P (2003) Aliased tidal signatures in continuous GPS height time series. Geophys Res Lett 30(23) 2184 doi:10.1029/2003GL018828

Saastamoinen J (1972) Atmospheric correction for the troposphere and stratosphere in radio ranging of satellites. In S.W. Henriksen et al. (ed) "The Use of Artificial Satellites for Geodesy", Geophys. Monogr. Ser., Vol. 15,.pp. 247251, American Geophysical Union, Washington,

SATREF (2007) [online] SATREF. http://www.satref.no/, (cited Jan 2009).

Scherneck H-G, Johansson JM, Elgered G, Davis JL, Jonsson B, Hedling G, Koivula H, M Ollikainen, Poutanen M, Vermeer M, Mitrovica JX, Milne GA (2002) BIFROST: Observing the Three-Dimensional Deformation of Fennoscandia. In Ice Sheets, Sea Level and the Dynamic Earth; Geodynamic series 29; American Geophysical Union.

Scherneck H-G, Lidberg M, Haas R, Johansson J M, Milne G A (2009) BIFROST Project: Contemporary Strain Rates in Fennoscandia from Eleven Years of Continuous GPS. This issue, submitted.

SOPAC (2009) [online] Scripps Orbit and Permanent Array Center http://sopac.ucsd.edu/ (cited Jan 2009)

SWEPOS (2007) [online] SWEPOS, A national network of reference stations for GPS. http://swepos.lmv.lm.se/english/index.htm, (cited Jan 2009).

Stewart M P, Penna N T, Lichti D D (2005) Investigating the propagation mechanism of unmodelled systematic errors on coordinate time series estimated using least squares. J Geod 79(8) 479-489 doi:10.1007/s00190-005-0478-6.

Tesmer V., J. Boehm, R. Heinkelmann, H. Schuh (2007). Effect of different tropospheric mapping functions on the TRF, CRF, and position time-series estimated from VLBI. Journal of Geodesy, 81 (6-8), pp. 409-421. DOI: 10.1007/s00190-006-0126-9

Tregoning P, van Dam T (2005) Effects of atmospheric pressure loading and seven-parameter transformations on estimates of geocenter motion and station heights from space geodetic observations, J geophys Res, 110, B03408, doi:10.1029/2004JB003334.

Watson C, Tregoning P, Coleman R (2006) Impact of solid Earth tide models on GPS coordinate and tropospheric time series. Geophys Res Lett 33 L08306 doi:10.1029/2005GL025538.

Webb F H, Zumberge J F (1993) An introduction to the GIPSY/OASIS-II, JPL Publ., D-11088.

Wessel P, Smith WHF (1998) New, improved version of Generic Mapping Tools released, EOS Trans. Amer. Geophys. U. vol. 79 (47), pp579.

Williams SPD (2003) The effect of coloured noise on the uncertainties of rates estimated from geodetic time series, J. Geod, 76483-494, doi:10.1007/s001990-002-0283-4.

Williams SPD, Bock Y, Fang P, Jamason P, Nikolaidis RM, Prawirodirdjo L, Miller M, and Johnson DJ (2004) Error analysis of continuous GPS position time series, J. Geophys. Res., 109, B03412, doi:10.1029/2003JB002741.

Williams SPD (2005) Create and Analyse Time Series: CATS software V3.1.1, July 11, 2005. Proudman Oceanographic Laboratory

Williams SPD (2008) CATS: GPS coordinate time series analysis software. GPS solutions, vol. 12:147-153, doi:10.1007/s10291-007-0086-4.

Zumberge JF, Heflin MB, Jefferson DC, Watkins MM (1997) Precise point positioning for the efficient and robust analysis of GPS data from large networks. J. Geophys. Res., vol. 102, no. B3, pages 5005-5017, Marsh 10, 1997. 